\title{
Atomic pectroscopy 今 \\ Micro-XRF Study of the Troodontid Dinosaur Jianianhualong tengi Reveals New Biological and Taphonomical Signals
}

\author{
Jinhua Li, ${ }^{\mathrm{a}, \mathrm{b}, \dagger}$ Rui Pei,${ }^{\mathrm{c}, \mathrm{d}, \mathrm{e}, \dagger}$ Fangfang Teng, ${ }^{\mathrm{f}}$ Hao Qiu, ${ }^{\mathrm{a}}$ Roald Tagle, ${ }^{\mathrm{g}}$ Qiqi Yan, ${ }^{\mathrm{g}}$ Qiang Wang, ${ }^{\mathrm{c}, \mathrm{d}}$ \\ Xuelei Chu, and Xing $\mathrm{Xu}^{\mathrm{c}, \mathrm{d}, *}$ \\ a Key Laboratory of Earth and Planetary Physics, Institute of Geology and Geophysics, Chinese Academy of Sciences, Beijing 100029, P. R. China \\ b Laboratory for Marine Geology, Qingdao National Laboratory for Marine Science and Technology, Qingdao 266061, P. R. China \\ c Key Laboratory of Vertebrate Evolution and Human Origins, Institute of Vertebrate Paleontology and Paleoanthropology, Chinese Academy of Sciences, \\ Beijing 100044, P. R. China \\ d CAS Center for Excellence in Life and Paleoenvironment, Beijing 100044, P. R. China \\ e State Key Laboratory of Palaeobiology and Stratigraphy, Nanjing Institute of Geology and Palaeontology, Chinese Academy of Sciences, Nanjing 210008, \\ P. R. China \\ f Xinghai Paleontological Museum of Dalian, Dalian 116023, Liaoning, P. R. China \\ g Bruker Nano GmbH, Am Studio 2D, 12489 Berlin, Germany
}

Received: November 15, 2020; Revised: November 28, 2020; Accepted: November 28, 2020; Available online: December 01, 2020.

DOI: 10.46770/AS.2021.01.001

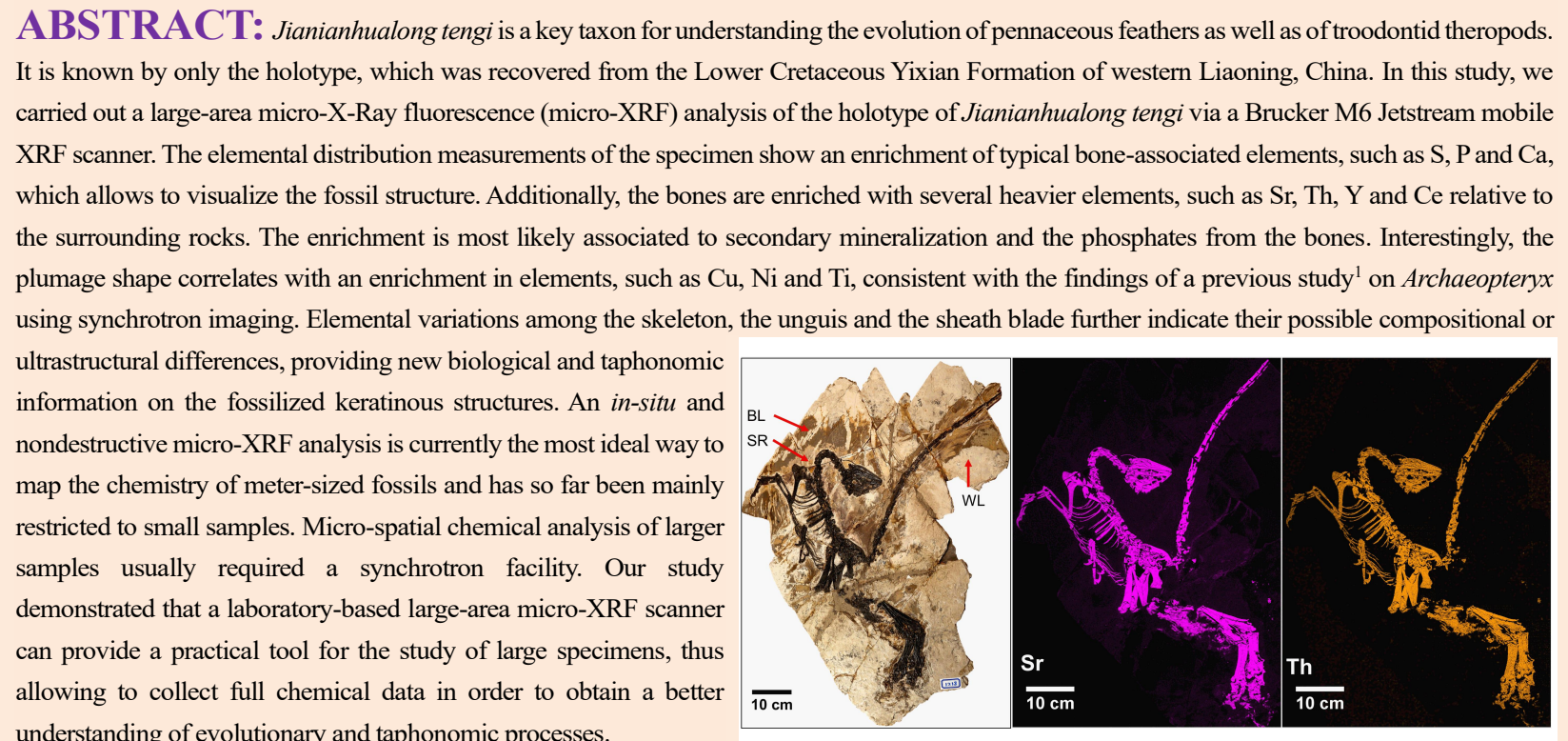

\section{INTRODUCTION}

Morphological studies on the skeleton and the plumage have forged a solid link between non-avialan coelurosaurians and birds, building a well-accepted framework for understanding the dinosaur-bird transition. ${ }^{2-4}$ Recent works started to look beneath the surface and into the ultrastructure and chemistry of fossil feathers and bones, and bring our understanding of this major transition to a new level. ${ }^{1,5-12}$ The chemistry of exquisitely preserved fossil animals, including several iconic flying/gliding theropods, have been investigated to reveal information on their paleobiology and the fossilization process. ${ }^{1,}$, , 9, 10, 12-14 Various chemical imaging techniques, e.g. Fourier-transform infrared (FTIR) spectroscopy, Raman spectroscopy, X-ray spectroscopy, 
and secondary-ion mass spectroscopy (SIMS), have been employed to track the molecular, elemental and isotopic information. 1, 5, 6, 8-13, 15-18 Unfortunately, previous studies all focused on non-destructive chemical imaging of small-sized specimens (e.g. Archaeopteryx, Confuciusornis), limited by the analytical instruments ${ }^{6,8,11,12}$ or the chemical analyses of small samples destructively taken from fossils. . $^{2} 10,13,16,17$ Up to now, systematic non-destructive chemical imaging on meter-sized specimens of non-avialan dinosaurs has not been carried out.

The Middle-Upper Jurassic and the Lower Cretaceous of western Liaoning and the neighboring areas have yielded abundant avialans and non-avialan dinosaur specimens with exquisite preservation of the soft tissues that enlightened our understanding of the origin and early evolution of feathers and bird flight. ${ }^{3,}$ 19-22 The unique preservation of these specimens also provides a good opportunity to detect the hidden ultrastructural, chemical and taphonomic information on feathers and bones. ${ }^{8-10 \text {, }}$ 16,23 The troodontid theropod Jianianhualong tengi is represented by an exquisitely preserved specimen from the Lower Cretaceous Yixian Formation. ${ }^{24}$ Using regular tools and laser-stimulated fluorescence imaging, it revealed to have asymmetrical pennaceous feathers, suggesting feather asymmetry, a synapomorphy of the Paraves, a clade including birds and their close relatives. Compared to other Mesozoic paravians with asymmetrical pennaceous feathers, Jianianhualong tengi is over one meter long and apparently not adapted for flight as indicated by its short forelimbs. ${ }^{24}$ Besides the novelty of feathers, Jianianhualong tengi is also featured by a mosaic combination of primitive and derived troodontid features. ${ }^{24}$

In this study, we performed several micro-X-Ray fluorescence analyses (micro-XRF) using the portable Bruker M6 Jetstream Xray fluorescence (XRF) scanner of the holotype of Jianianhualong tengi to reveal the chemistry of the whole specimen as well as some of its relevant features. The mobility of the instrument provides ideal conditions (detailed in the Materials and Methods section) for in-situ micro-XRF measurement and highperformance elemental distribution analysis of large samples (over $0.6 \mathrm{~m}^{2}$ ) for the first time with a high spatial resolution in the 100 $\mu \mathrm{m}$ range. ${ }^{25-27}$ The analyses revealed new information for understanding the paleobiology of this troodontid dinosaur and the taphonomy of this important fossil.

\section{MATERIALS AND METHODS}

\section{Troodontid dinosaur Jianianhualong tengi}

The holotype, the only known Jianianhualong tengi specimen, was discovered from the Lower Cretaceous Yixian Formation (the middle section of the Jehol group) of Baicai Gou, Yixian County, western Liaoning, China. The holotype (DLXH 1218) is now housed at the Dalian Xinghai Museum (DLXH). Unlike other troodontid specimens from the Yixian Formation that are 3D- preserved in tuffaceous sandstones, DLXH 1218 is compressed and preserved on a tuffaceous shale slab, even though the bones are not entirely flattened (Fig. 1a). The shale slab was broken into several pieces while being collected and was glued together when the fossil was prepared. DLXH 1218 contains a nearly complete skeleton associated with soft tissues, including feathers (Fig. 1a). The skeleton is black in color. At least two layers of the matrix can be observed on the slab: an overlying white layer (WL) and an underlying brown layer (BL, possibly rich in organic matter) that preserve the fossil. The immediate areas surrounding the skeleton, possibly soft remains (SR) of the specimen, have a brighter color than the remaining parts of the matrix consisting of a brown layer (Fig. 1a). The size of the slab is approximately $90 \mathrm{~cm}$ long and 70 cm wide. DLXH 1218 measures $\sim 100 \mathrm{~cm}$ in preserved skeletal body length and $\sim 117 \mathrm{~mm}$ in femoral length. DLXH 1218 is estimated to be $\sim 112 \mathrm{~cm}$ in total length with a fully preserved tail.

\section{Micro-XRF imaging and data analysis}

The elemental maps of the specimen DLXH 1218, were obtained using the Bruker M6 Jetstream mobile X-ray fluorescence (XRF) scanner which permits large surface scanning with a lateral resolution up to $50 \mu \mathrm{m}$. The analysis was performed at the Dalian Xinghai Museum for in-situ studies (Fig. S1a). The Bruker M6 Jetstream consists of a mobile measuring head that can scan the surface of a sample on a XY-motorized stage (Fig. S1b). The maximum range of the $\mathrm{XY}$-motorized stage is $800 \mathrm{~mm} \times 600 \mathrm{~mm}$ $(\mathrm{H} \times \mathrm{W})$. Mounted on the measuring head is a Rh-target X-ray tube $(30 \mathrm{~W}$ maximum power, usually operated at $50 \mathrm{kV}$ and a maximum current $0.6 \mathrm{~mA}$ ). The X-ray beam is guided to the sample through polycapillary focusing optics. The beam diameter can be regulated by adjusting the distance between the X-ray source and the sample surface, the standard settings are between $100 \mu \mathrm{m}$ and $500 \mu \mathrm{m}$. The X-ray signal from the sample is collected with a $30 \mathrm{~mm}^{2}$ XFlash silicon drift detector with an energy resolution $<145 \mathrm{eV}$ at $\mathrm{Mn}-\mathrm{K} \alpha$. The instrument is equipped with two magnifying optical cameras to document the area of analysis. The portability of the instrument allows to bring the instrument to the object and to measure the samples directly on-site, reducing the risk of transport damage of valuable samples. This provides ideal conditions for an in-situ micro-XRF measurement for high performance element distribution analysis of large samples with high spatial resolution in the $100 \mu \mathrm{m}$ range. ${ }^{25-27}$

The specimen was placed horizontally on a table and properly oriented (Fig. S1b), then scanned fully (the whole specimen) and partially (several sub-areas of interest with higher resolution). Fullarea XRF elemental maps of DLXH 1218 are shown in Fig. 1 and Fig. S2. The acquisition conditions were $1500 \times 1090$ pixel for a total of 1.635 million pixel/map, and the acquisition time per pixel was $15 \mathrm{~ms}$ with a pixel size of $500 \mu \mathrm{m}$. The total measurement time was 9 h $30 \mathrm{~min}$ (Fig. 1). The feather and bone chemistry were further studied via in-situ micro-XRF imaging on several subareas of interest using higher spatial resolution. The acquisition 

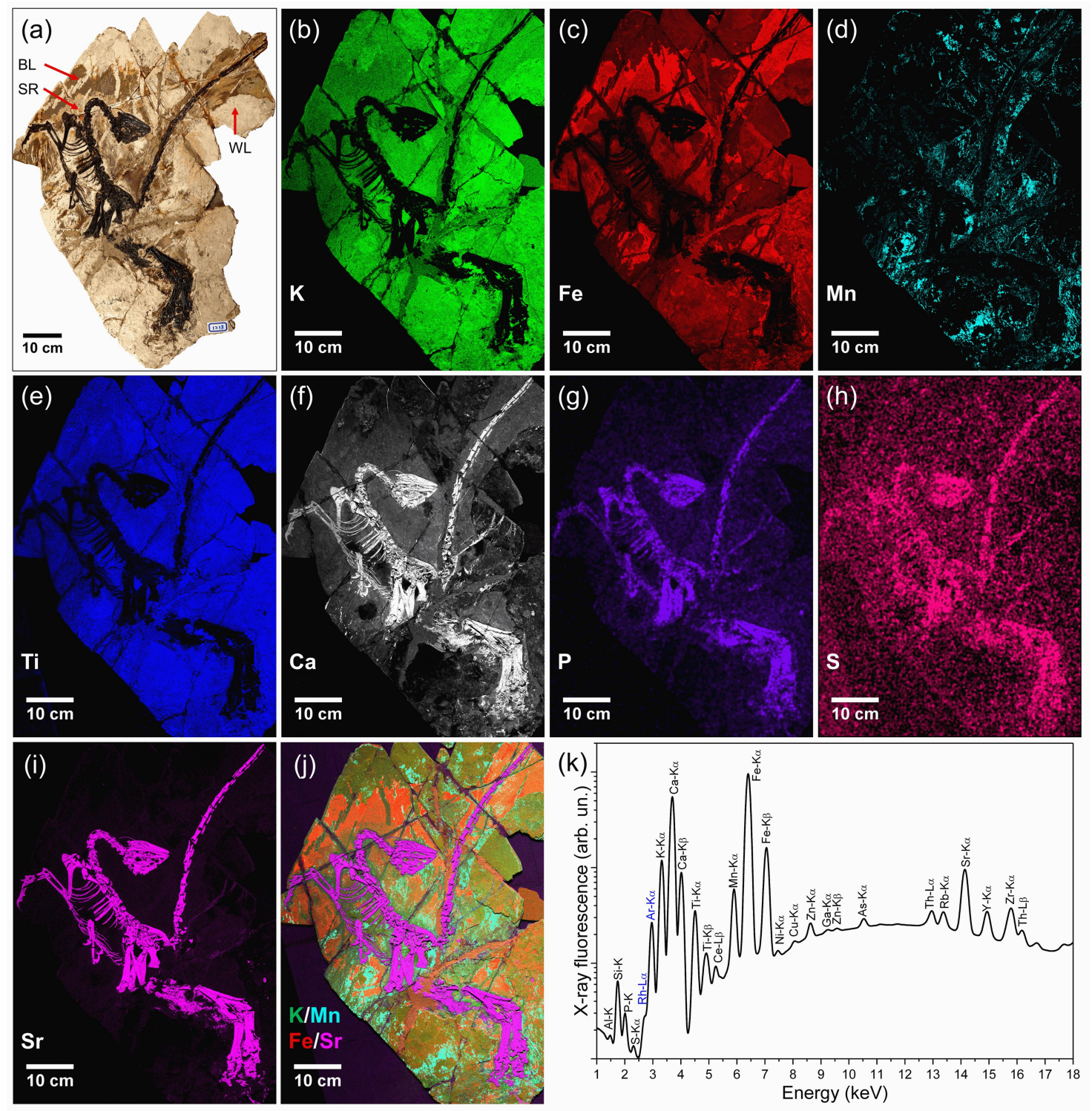

Fig. 1 Overall elemental distribution of the holotype of Jianianhualong tengi revealed via micro-XRF imaging. (a) Light photo of Jianianhualong tengi (DLXH 1218). The skeleton of the fossil is represented in black color. The matrix contains an overlaying white layer (WL), a brown layer (BL), and an immediate layer surrounding the skeleton, possibly soft remains (SR) of the specimen. (b)-(i) Micro-XRF detail maps (false-color images) of K-K $\alpha$ (b), Fe-

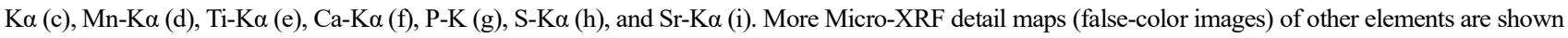
in the supplementary material (Fig. S1). (j) Combined map of four elements. Green, K; aqua, Mn; red, Fe; magenta, Sr. (k) The corresponding XRF spectrum shows the detectable elements of $\mathrm{Al}, \mathrm{Si}, \mathrm{P}, \mathrm{S}, \mathrm{K}, \mathrm{Ca}, \mathrm{Ti}, \mathrm{Ce}, \mathrm{Mn}, \mathrm{Fe}, \mathrm{Ni}, \mathrm{Cu}, \mathrm{Zn}, \mathrm{Ga}, \mathrm{Zn}, \mathrm{As}, \mathrm{Th}, \mathrm{Rb}, \mathrm{Sr}, \mathrm{Y}$ and $\mathrm{Zr}$. The Rh and Ar peaks originate from the Rh-target microfocus-X-ray tube and ambient air, respectively.

conditions for the tail measurements were $393 \times 193$ pixel for a total of $75.849 \mathrm{k} \mathrm{pixel} / \mathrm{map}, 100 \mathrm{~ms} /$ pixel with the pixel size of 400 $\mu \mathrm{m}$, and $2 \mathrm{~h} 17 \mathrm{~min}$ total measurement time (Fig. 2). The acquisition conditions for the pelvis and the hind limb measurements were $848 \times 584$ pixel for a total of $495.232 \mathrm{k}$ pixel/map, $10 \mathrm{~ms} /$ pixel with the pixel size of $250 \mu \mathrm{m}$, and $1 \mathrm{~h} 57$ min total measurement time (Fig. 3). The acquisition conditions for the cranium measurements were $484 \times 555$ pixel for a total of $268.620 \mathrm{k} \mathrm{pixel} / \mathrm{map}, 20 \mathrm{~ms} /$ pixel with the pixel size of $200 \mu \mathrm{m}$, and $1 \mathrm{~h} 51 \mathrm{~min}$ total measurement time (Fig. 4). The acquisition conditions for the pes measurements were $515 \times 372$ pixel for a total of $191.580 \mathrm{k} \mathrm{pixel} / \mathrm{map}, 20 \mathrm{~ms} /$ pixel with the pixel size of 400 $\mu \mathrm{m}$, and $1 \mathrm{~h} 25 \mathrm{~min}$ total measurement time (Fig. 4).

The XRF spectra were collected, deconvoluted and examined based on the 2D maps of the XRF data, with each pixel in the map holding an XRF spectrum that can be analyzed. XRF raw data is the collection of counts of element-specific fluorescent X-ray signals received by the XRF instrument detector. Therefore, chemical elements were identified based on the peaks in the XRF spectra corresponding to the characteristic X-ray emission lines of each element. The sum of the counts of a particular peak or an X- 

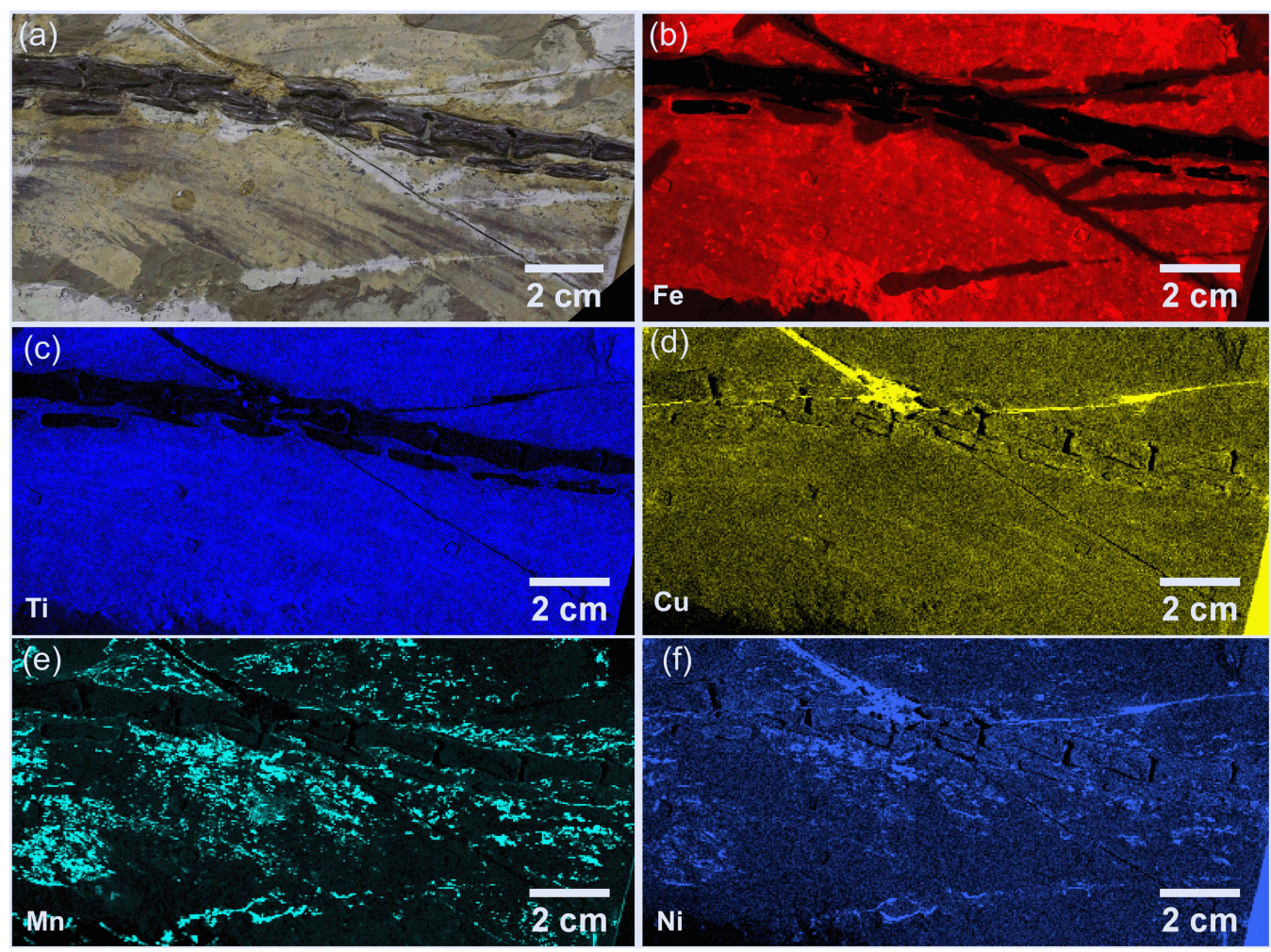

Fig. 2 (a) Light photo of a small region of the Jianianhualong tengi tail. (b)-(f) Micro-XRF detail maps (false-color images) of Fe (b), Ti (c), Cu (d), Mn (e), $\mathrm{Ni}$ (f) distribution within bone materials and feathers of the Jianianhualong tengi tail.

ray emission line or family of X-ray emission lines is often in proportion to the concentration of the relevant element. ${ }^{28}$ In order to compare the chemical composition of the specimen further, various regions of interest (ROI) were selected for semiquantitative analysis (Tables S1-S4). In addition, principal component analysis (PCA) was applied to improve the XRF spectrum for each component. ${ }^{29}$

It should be noted that the given analytical conditions could not provide true values of the concentration of each element. Usually, a quantitative XRF analysis can be done based on empirical models (standard-based) or Fundamental Parameters (FP). Empirical models require matrix-matched standards, but no appropriate standards for this application exist at this time. FP models require all elements including carbon to be analyzed, but the carbon concentration could not be assessed since carbon cannot be measured in an open beam XRF system because of air absorption. In addition, DLXH 1218 is not entirely flat. As a result, the distance between the object and the instrument as well as the orientation between the object and the excitation-detector plane can be different at any given location. Therefore, semi-quantitative data processing was used here to assess the relative elemental concentrations between ROIs.

\section{RESULTS AND COMPARISONS}

Overall elemental distribution revealed via full-area XRF imaging

The XRF measurements performed provide an overall distribution of at least 20 recognizable elements in the specimen (Fig. 1k). Sorting of the elements by their main phase shows that the light rock where the fossil is embedded is rich in $\mathrm{Si}, \mathrm{K}, \mathrm{Ca}, \mathrm{Ti}, \mathrm{Mn}$, and $\mathrm{Fe}$ (note that all elements are most likely present as oxides, but the oxygen cannot be detected here) (Fig. 1, Fig. S2). The elements present and their respective intensities suggest a clay rich sedimentary rock with a carbonate fraction.

The areas with high $\mathrm{Mn}$ are scattered on the white layer (represented by the black spots under normal light). This is most likely related to pyrolusite mineralization $\left(\mathrm{MnO}_{2}\right)$. The darker parts in the visual image of DLXH 1218, some of them associated to feathers, correlate with an increase in Fe and As. The Fe and As levels are very low in the skeleton. They are most concentrated in the brown layer and less concentrated in the overlying white layer (Fig. 1c, Fig. S2f). The soft tissue remnants including the feathers (represented by the light brown areas close to the skeleton under visible light) exhibit lower Fe levels than the immediate surrounding matrix (the brown layer) (Fig. 1c). Rubidium and Ga are possibly controlled by the matrix. They are high in the white layer of the matrix, slightly lower in the brown layer of the matrix, and extremely low in the skeleton (Fig. S2d, S2e).

Zinc is distributed primarily in the white layer of the matrix and the cement-like material (Fig. S2i). The various rock fragments of 

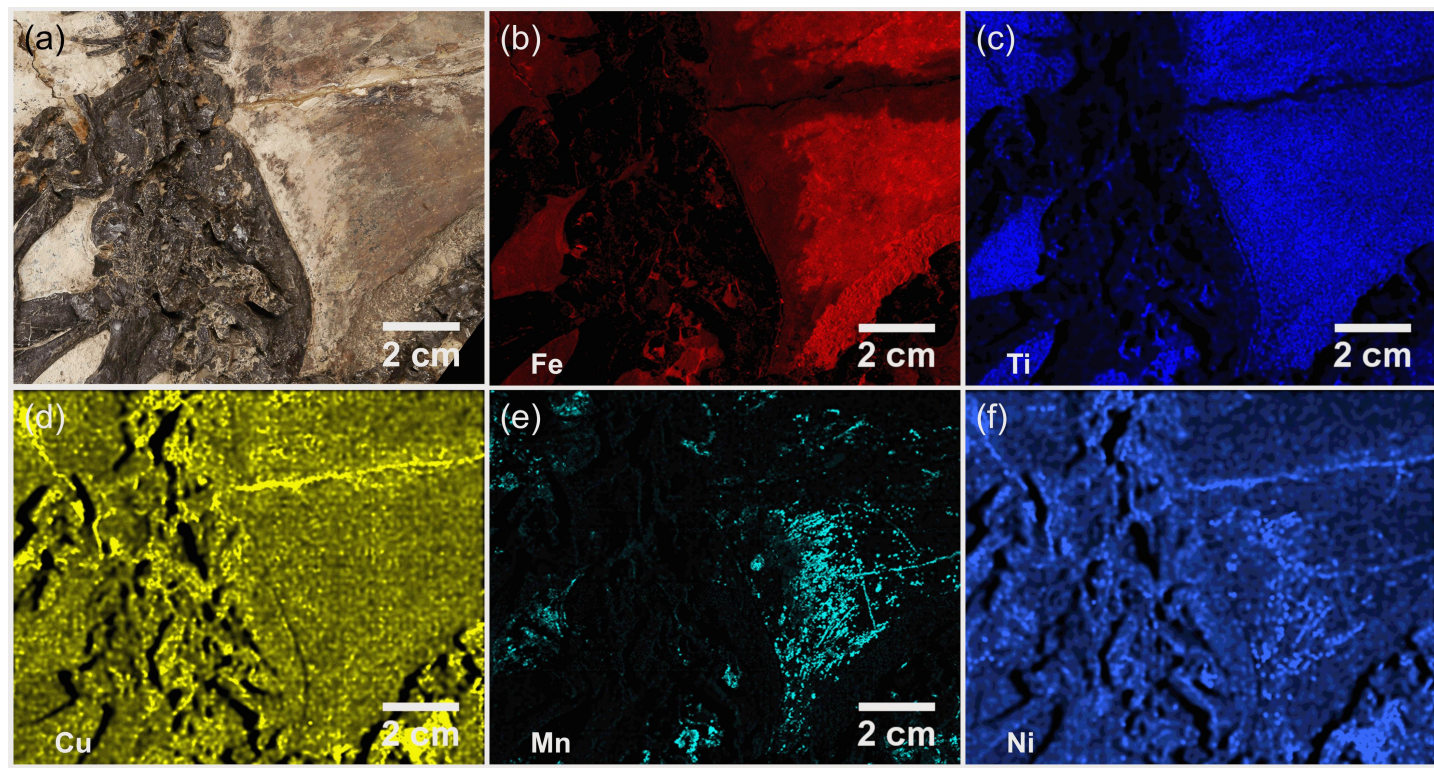

Fig. 3 (a) Light photo of a small region of the Jianianhualong tengi hip. (b)-(f) Micro-XRF detail maps (false-color images) of Fe (b), Ti (c), Cu (d), Mn (e), $\mathrm{Ni}$ (f) distribution within bone materials and feathers of the Jianianhualong tengi hip.

the fossil is glued together with a cement-like material, containing some traces of $\mathrm{Zn}$. The $\mathrm{Zn}$ level is low in the skeleton and the soft tissue including the feather remnants, which contradicts the results observed in the Thermopolis Archaeopteryx where the bone materials have a higher $\mathrm{Zn}$ level than the feathers and the matrix. ${ }^{12}$ As a contrast, the coliiformes bird has a higher $\mathrm{Zn}$ level in the feathers, while the matrix and the bones contain less $\mathrm{Zn} .{ }^{30}$

The bone is, as expected rich, in $\mathrm{Ca}$ and $\mathrm{P}$, corresponding mineralogically to apatite (Fig. 1f, g). The apatite mineral appears strongly enriched several incompatible elements such as: $\mathrm{Th}, \mathrm{Sr}$, and $\mathrm{Y}$ as well as some REE mainly Ce (Fig. S1, Tables S1-S4). Comparatively, Sr, Y, Th and Ce levels seem heavily associated with the skeleton and are relatively low in other regions including the slab matrix and the soft tissue remains, as mentioned above. A high $\mathrm{Ca}$ level associated with $\mathrm{Sr}$ and $\mathrm{Y}$ was noticed in both vertebrate and invertebrate fossil materials. ${ }^{31}$

\section{Elements associated with the feathers}

The regions where feather remains can be observed show an enrichment and correlation pattern of several elements including $\mathrm{Mn}, \mathrm{Ti}, \mathrm{Ni}$ and $\mathrm{Cu}$ (Fig. 1, Fig. S1). This is most visible for the feather region in the detail scan of the tail see in Fig. 2. Whereas an integration of transitional elements such as $\mathrm{Mn}, \mathrm{Cu}$ and $\mathrm{Ni}$ into the organic component appears more obvious, is the enrichment of Ti in Fig. 2c is more difficult to explain, especially since the correlation of $\mathrm{Ti}$ with the feather structure is much clearer than for the other elements as can be seen in the scan from the tail (Fig. 2).

As shown in Fig. 2a, 2c-2f and Fig. 3a, 3c-3f, the distributions of $\mathrm{Ti}, \mathrm{Cu}, \mathrm{Mn}$, and $\mathrm{Ni}$ match well with the stripe pattern of the feathers. The enrichment of many of these elements associated to the feather-structure has also been previously reported in synchrotron studies of fossil feathers. ${ }^{1,6,12}$ The Fe level seems relatively lower in the feathers than of the immediate surrounding body tissue, while $\mathrm{Ti}, \mathrm{Cu}, \mathrm{Mn}$ and $\mathrm{Ni}$ seem relatively higher in the feathers rather than in the immediate surrounding body tissue (Fig. 2). Notably, unlike the striped pattern seen on the tail feathers (Fig. 2d), the pattern of $\mathrm{Cu}$ is not clearly associated with the feathers on the pelvis (Fig. 3d). The $\mathrm{Cu}$ and Mn levels apparently vary for feathers on different parts of the body. The tail feathers have richer $\mathrm{Cu}$ than the pelvis feathers, while the Mn level is higher in the pelvic feathers than in the tail feathers (Tables S1S3). However, these variations in the feather samples are not found for $\mathrm{Fe}$, Ti and Ni. Even though $\mathrm{Zn}$ as well as $\mathrm{Ca}, \mathrm{Fe}, \mathrm{Cu}$ and $\mathrm{Mn}$ are known to be typically associated with melanin pigmentation, ${ }^{1,}$ $6,11,32,33$ we did not find a connection between $\mathrm{Zn}$ and the feathers on DLXH 1218.

$\mathrm{Cu}$ and $\mathrm{Ni}$ appear also distributed in the bone materials, while $\mathrm{Fe}$, $\mathrm{Ti}$ and $\mathrm{Mn}$ are not significantly enriched in the bones (Figs. 2, 3). Copper and $\mathrm{Ni}$ are distributed in the white layer of the matrix and slightly more concentrated in the feathers. Both elements are less accumulated in the bone materials and in the brown layer of the matrix, and high concentrations appear in the glue which was used for fossil restoration (Fig. S2g, S2h). A high level of $\mathrm{Cu}$ and $\mathrm{Ni}$ is also known to be in the feathers of many fossil and living taxa, such as Anchiornis, Archaeopteryx, Gansus and other fossils and living birds. ${ }^{1,6,8,12,30,32}$ In all of these specimens and DLXH 1218, the $\mathrm{Cu}$ level is generally higher in the feathers than in the bones, and the $\mathrm{Cu}$ concentration usually varies for the different feather samples of the individual specimen. $6,12,30,32$

\section{Sr- and Ca-XRF imaging the morphology and preservation of the skeleton}




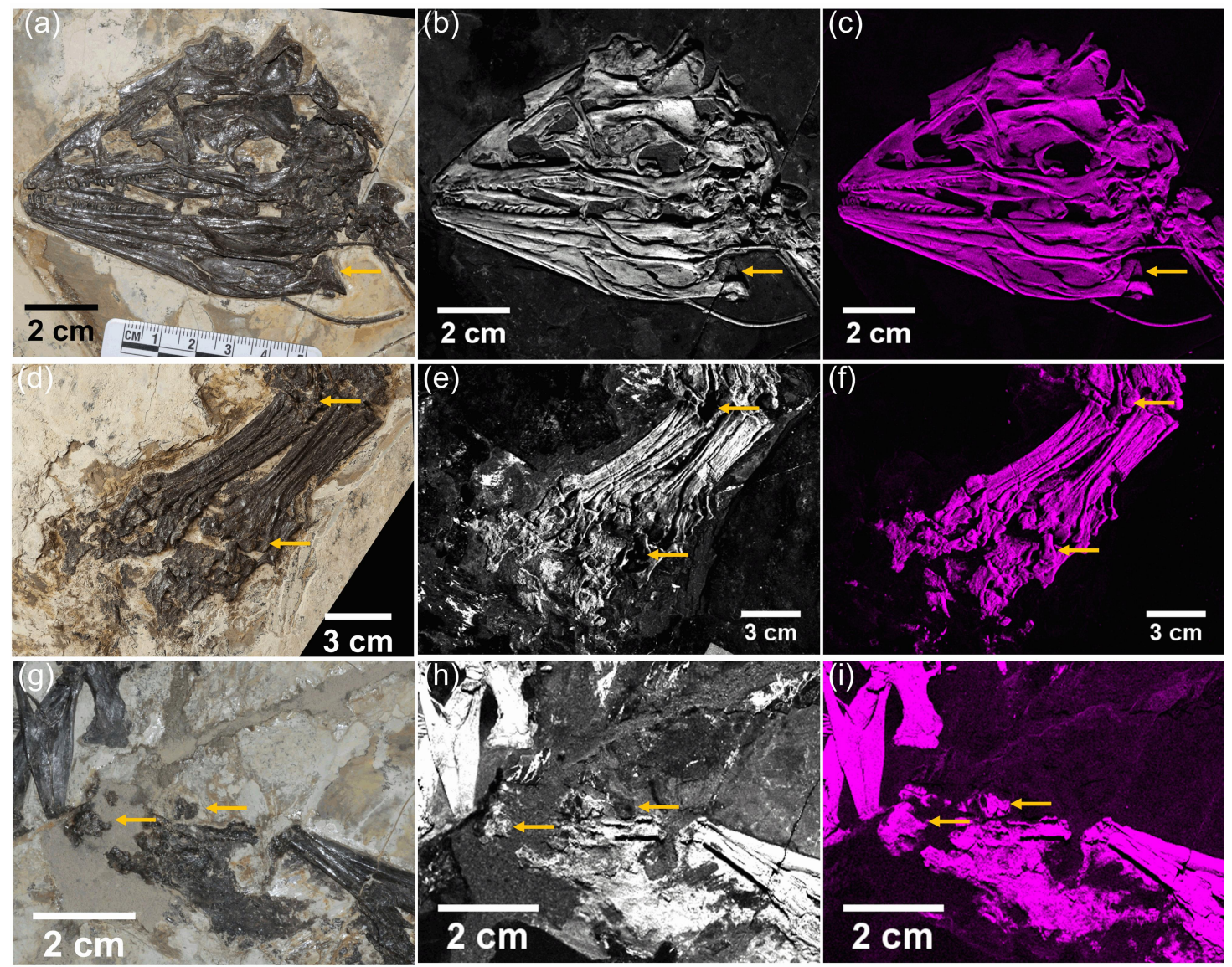

Fig. 4 Micro-XRF detail maps (false-color images) of Ca and Sr distribution within the cranium (a)-(c), the pes (d)-(f), and the pelvis and the tibiotarsus (g)(i) of the Jianianhualong tengi. The first column indicates the corresponding light photos, the second for Ca distribution maps, the third for Sr distribution maps. Arrows indicate regions with calcium removal.

The elements $\mathrm{Sr}$ and $\mathrm{Ca}$ were found in the bone materials, but $\mathrm{Ca}$ is also observed in the soft tissue remains and on the slab. In contrast, $\mathrm{Sr}$ seems to be heavily and uniformly present in the skeleton, but at very low levels in other regions (Figs. 1, 4). The $\mathrm{Sr} / \mathrm{Ca}$ ratio is generally consistent for most parts of the skeleton (0.26 0.41, Tables S1-S4). Fig. 4 shows a comparison of the XRF maps of $\mathrm{Ca}$ and $\mathrm{Sr}$ in the cranium, the pes and the hind limb. Though no novel morphologies were revealed via chemical imaging, it is clear that, compared to the Ca-maps, the Sr-maps significantly improve the skeletal image by having a better contrast and making the sutures and outlines of the bones more visible. This is possibly due to the fact that $\mathrm{Sr}$ is only rich in the skeleton, or has a better lateral resolution than $\mathrm{Ca}$, or both. Furthermore, comparisons between the $\mathrm{Ca}$ and $\mathrm{Sr}$ elemental maps may also provide insight into the taphonomy and the process of fossilization.

For instance, the pedal digits, the right metatarsus and the right calcaneum ( $\mathrm{Sr} / \mathrm{Ca}$ ratio $\sim 0.83$ ) show distinct $\mathrm{Ca}$ loss compared to other parts of the skeleton, while the Sr level remains stable. Since there is damage to the bone, it is possible that this makes Ca easier to be carried away during fossilization (Fig. 4). Similarly, a low $\mathrm{Ca}$ level is present ventral to the distal dorsal process of the right ischium possibly due to a breakage in that bone. On the other hand, the Sr map shows the complete shape of the distal dorsal process of the ischium (Fig. 4), resulting from a relatively stable Sr level for that area.

Ambiguously shaped dark-colored matter is preserved near the hind limbs of DLXH 1218, close to the proximal portion of the tibiotarsus and the distal region of the pes (Fig. 4d-4f, Tables S3, $\mathrm{S} 4)$. The high $\mathrm{Sr}$ levels and the high $\mathrm{Sr} / \mathrm{Ca}$ ratio $(\sim 0.59)$ match the shape of the dark-colored regions, reaffirming that these are remains of smashed bone materials rather than imprints of feathers or other non-skeletal structures, especially considering the proximal portion of the tibiotarsus is severely fragmented and the pedal digits are damaged, which makes the bone materials easily scattered around the damaged bone.

It should be pointed out that a careful examination of the specimen does not reveal new morphology that has not already been observed under normal light. No trace of cartilage remains were associated with the sternum with regard to the $\mathrm{Ca}$, Sr or other elemental maps (Fig. S4), which supports the hypothesis that sternal plates are absent in troodontids. ${ }^{34}$ 

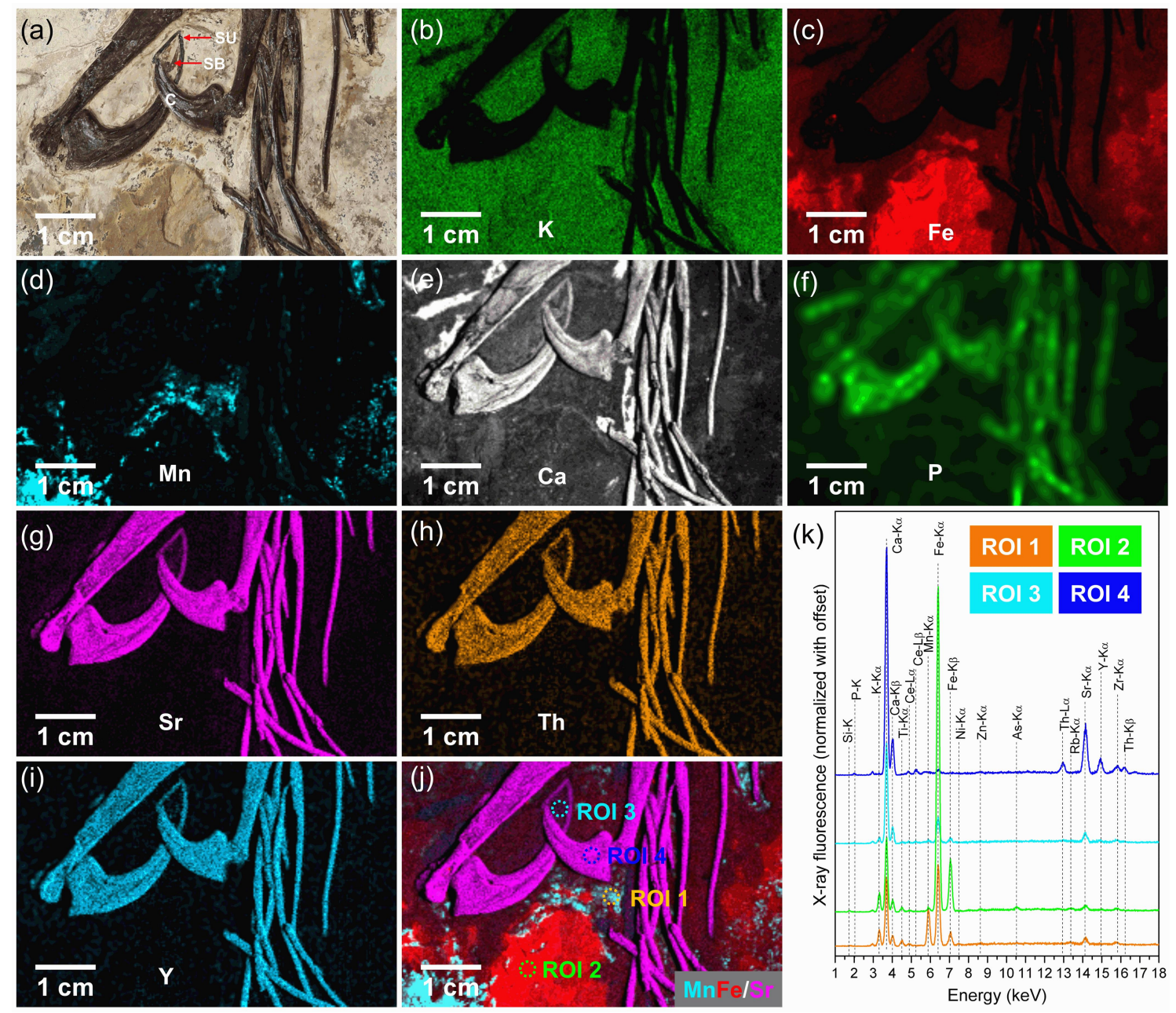

Fig. 5 (a) Light photo of a small region of the Jianianhualong tengi claw. The bony claw (C), the unguis (SU) and the sheath blade (SB) can be observed based on light photo imaging (a). (b)-(j) Micro-XRF detail maps (false-color images) of K (b), Fe (c), Mn (d), Ca (e), P(f), Sr (g), Th (h), and Y (i) distribution within the bone and sheath materials of the Jianianhualong tengi claw. (j) Combined map of three elements. Aqua, Mn; red, Fe; magenta, Sr. (k) XRF spectra originating from the four small regions of interest (ROI) circled in different colors in the panel (j). ROI 1 and 2 are white and brown regions of the matrix, respectively, ROI 4 indicates the region of the bony claw, and ROI 3 is the region containing the sheath blade.

\section{Structure and chemistry of the claw sheath}

Interestingly, the claw sheaths showed elemental signatures that were previously not noted by using chemical imaging (Figs. 5, 6). In DLXH 1218, the sheaths surrounding the distal portion of the manual and pedal distal phalanges are preserved. The sheaths have elevated $\mathrm{Ca}, \mathrm{P}, \mathrm{Sr}, \mathrm{Th}$, and $\mathrm{Y}$ levels relative to the matrix, but very low $\mathrm{K}, \mathrm{Fe}$ and $\mathrm{Mn}$ levels, which matches the pattern of other bones (Fig. 5, Table S3). A high P profile of the sheaths was also noticed in the Thermopolis Archaeopteryx, Shuvuuia and Citipati. ${ }^{12,35,36}$ The $\mathrm{Ca}$ level is relatively low in the sheath as a result of richer $\mathrm{Ca}$ in the matrix of the Thermopolis Archaeopteryx, ${ }^{12}$ yet a high Ca level is present in the sheaths of Citipati and Shuvuuia ${ }^{12,35,36}$ as in Jianianhualong tengi, indicating preservation as calcium phosphate. The $\mathrm{S}$ level is higher in the sheaths than in the matrix of DLXH 1218 as in the Thermopolis Archaeopteryx and Shuvuuia. ${ }^{12,35}$
Detailed examination of the claw sheaths of DLXH 1218 (Figs. 5,6 ) revealed a chemical pattern that was not observed in previous studies. ${ }^{12,35,36}$ No differences were noticed between the bony and keratinous structures of the claw in the Thermopolis Archaeopteryx, ${ }^{12}$ but the thickened dorsal rim of the sheath (unguis) of DLXH 1218 exhibits slightly lower levels of Sr, Th and $\mathrm{Y}$ than the bony digit (Figs. 5g-i, Table S3), while the Ca level is similar to that in the bony parts (Figs. 5e, Table S3). However, the flattened sheath blade exhibits even lower Sr, Th, Y and Ca than the unguis. The $\mathrm{Sr} / \mathrm{Ca}$ ratio is also much lower in the sheath blade than in the unguis, but this ratio resembles that of the feathers, even though the Ca concentration is still higher in the sheath blade than in the feathers (Fig. 6, Table S3). Unlike the bony ungual digits, claw sheaths are modified scales in reptiles and birds, composed of beta keratins over alpha keratins, ${ }^{37,} 38$ yet the elemental signature of the unguis resembles that of the bony claw 

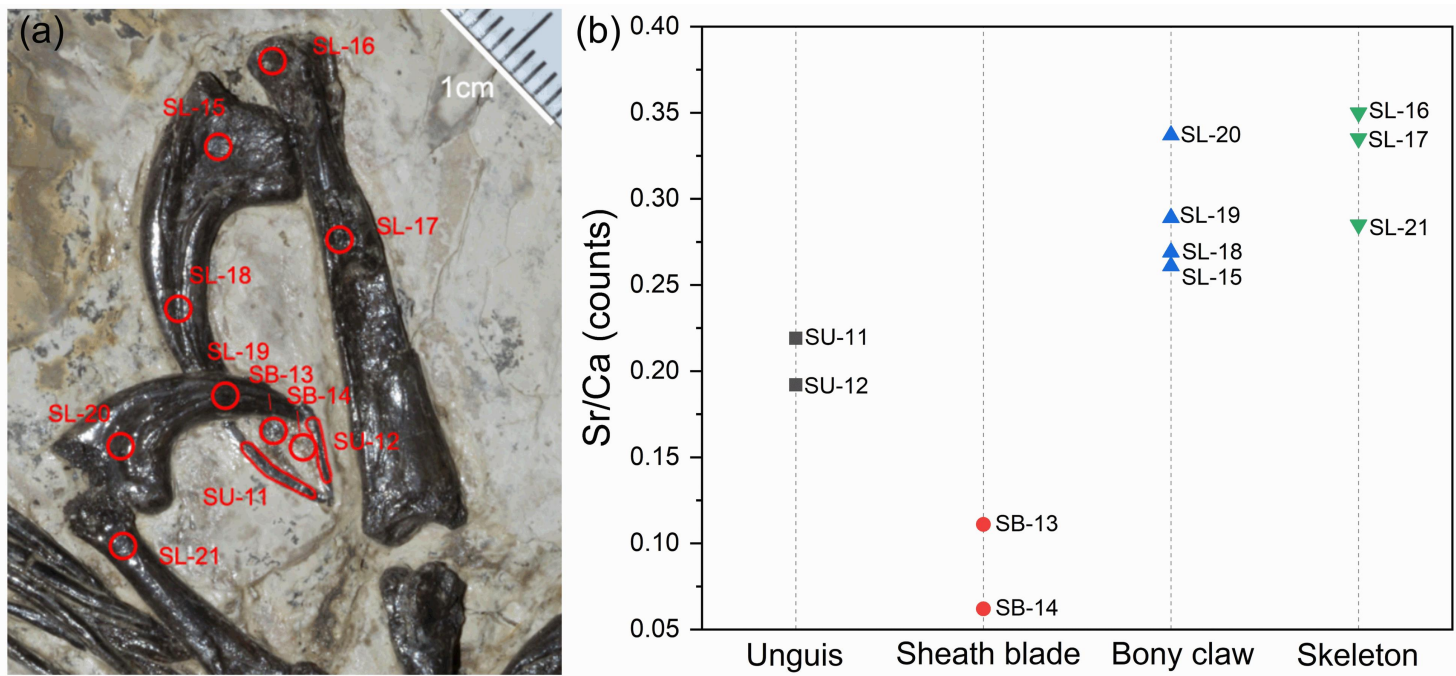

Fig. 6 (a) Regions of interest associated with the claw of Jianianhualong tengi, and (b) Sr/Ca ratios of each region. SB, sheath blade; SU, unguis; SL, skeleton and bony claw.

rather than the sheath blade and the keratinous feathers. Previous studies showed that extant archosaurian unguis developed from denser corneous materials than the sub-unguis. ${ }^{37,38}$ Calcification of keratin has also been observed occasionally in dense and hardened keratinous structures in extant animals ${ }^{39,45}$ and therefore, a similar calcification process of the keratins may also be present in this Mesozoic theropod in vivo, which caused the enrichment of $\mathrm{Ca}$ and a higher $\mathrm{Sr} / \mathrm{Ca}$ ratio in the unguis than in the sheath blade.

\section{DISCUSSION}

\section{Information revealed by micro-XRF chemical imaging}

Applying large-area micro-XRF on DLXH 1218 helped to reveal the surface elemental distribution in the biological remains of the specimen and its surrounding geological matrix. Unlike chemical mappings in previous studies that focus on the lighter elements, ${ }^{12}$, ${ }^{30}$ micro-XRF imaging is also able to detect the distribution of heavier elements. Generally, the distribution of $\mathrm{Ti}, \mathrm{Cu}, \mathrm{Mn}$ and $\mathrm{Ni}$ is associated with the soft remains, which match well with the pattern of the feathers. The heavier elements of Sr, Th, Y and Ce are strongly associated with the skeleton. Though no novel morphology was uncovered by chemical mapping, compositional variations were found in some structures to reflect either biological or taphonomic features. For instance, the $\mathrm{Sr}$ variation among the unguis, the sheath blade and the bony claw likely indicate the compositional differences among these structures. The $\mathrm{Ca}$ variation in some parts of the skeleton (e.g. between pedal digits and the metatarsus) possibly showed Ca loss during fossilization.

Combining chemical information of the lighter and heavier elements can provide insight into the material exchange of the fossil remains and the surrounding rocks during fossilization. Notably, a crack-like structure posterior to the proximal caudal showed interesting elemental abnormalities (Fig. 1). The Ca, P and $\mathrm{S}$ levels in this crack are similar to that of the skeleton, while the $\mathrm{Sr}, \mathrm{Th}, \mathrm{Y}$ and Ce levels are very low in this crack in comparison to the bones. Unlike other cracks that were filled with glue during fossil preparation, the $\mathrm{As}, \mathrm{Cu}, \mathrm{Ni}, \mathrm{Ga}$ and $\mathrm{Zn}$ levels are also low in this crack (Fig. 1, Fig. S2). Therefore, we infer that this crack was likely formed during fossilization, and the water flux carried the lighter elements of $\mathrm{Ca}, \mathrm{P}$ and $\mathrm{S}$ from the animal remains into this crack. On the other hand, the heavier elements, such as Sr, Th, Y and $\mathrm{Ce}$, more easily accumulated in the bone materials and were not carried away by water flux. This may further indicate that at least part of these heavier elements in the skeleton are original, as can be supported by the fact that Sr participates significantly in bioapatite mineralization throughout the life of an animal. ${ }^{40}$

\section{Comparisons with chemistry of other fossil materials}

A comparison of the chemical mapping of DLXH 1218 and other vertebrate fossils not only shows consistent patterns of chemical accumulation in the bones and feathers, but also indicates that elements behave differently depending on the chemical composition of the surrounding rocks, as previously reported. ${ }^{8,31}$, ${ }^{41}$ Rossi and co-workers ${ }^{14}$ concluded that the elemental signature of vertebrate fossils is tissue-specific and controlled by many biological and environmental factors, which is in agreement with our findings for DLXH 1218, namely, that the similarities and differences in the elemental distribution in the feathers and bones can be compared with finding for other vertebrate fossils. Since the composition of bones is representative of a particular depositional environment and most likely also the local condition where fossilization occurred, this variation of local compositional fingerprint could be used to assign poorly or not correct documented fossil to certain location. For this purpose, additional systematic work is needed. 
Specifically, S, P and $\mathrm{Ca}$ are the most commonly examined elements in chemical studies based on fossil materials. ${ }^{31,42}$ Consistently, micro-XRF with DLXH 1218 showed that S, P and $\mathrm{Ca}$ are associated with the organic matter (both the skeleton and soft tissues), while the Ca levels are slightly higher in the skeleton, a pattern similar to previously examined fossil specimens. ${ }^{1,12,32}$ Comparatively, the Ca level in the matrix of DLXH 1218 is relatively low, different from the Thermopolis Archaeopteryx, where the matrix rock is calcium-rich. ${ }^{12}$ The claw sheaths preserved in DLXH 1218 have elevated Ca and P levels, congruent with the patterns found in the Thermopolis Archaeopteryx, Shuvuuia and Citipati specimens. ${ }^{12,35,36}$

Some elements, such as $\mathrm{Ca}, \mathrm{Zn}, \mathrm{Mn}, \mathrm{Cu}$ and $\mathrm{Ni}$, have been associated with melanin pigmentation in modern and fossil feathers. ${ }^{1,6,11,18,30,32,33}$ In the fossils of Jianianhualong, Anchiornis, Archaeopteryx, Gansus, and other extinct and living birds, the $\mathrm{Cu}$ level usually varies with different feather samples of an individual and is generally higher in the feathers than in the bones. ${ }^{6,12,30,32}$ Though in DLXH 1218, the distributions of $\mathrm{Ca}, \mathrm{Cu}, \mathrm{Mn}$ and $\mathrm{Ni}$ match the plumage shapes, no obvious enrichment of $\mathrm{Zn}$ was observed with either the feathers or the bones, which is also different from the Thermopolis Archaeopteryx, Confuciusornis and the fossil coliiformes bird (AMNH FARB 30806) where the feathers and the bone materials have elevated $\mathrm{Zn}$ levels. ${ }^{6}$, 12, 30 Instead, the highest level of $\mathrm{Zn}$ is present in the glue added in DLXH 1218. In DLXH 1218, aside from the matching pattern of $\mathrm{Mn}$ and the pelvic feathers, high Mn level areas are also scattered on the sediments, similar to the Thermopolis Archaeopteryx and the Green River feathers (BHI-6358, BHI-6319), where the Mn level is generally higher in the matrix than in the feathers, ${ }^{12,32}$ but is unlike that in Confuciusornis, Gansus and the fossil coliiformes specimens, where $\mathrm{Mn}$ is rich in the feathers but absent in parts of the matrix.6, 30, 32 A high Ti level is also found in the feathers preserved in DLXH 1218, a pattern that has not been reported in other fossil materials, although a variation in Ti level has been detected between two Gansus feathers and in contrast, Ti is absent in some modern bird feathers. ${ }^{32}$

Though a high Fe level is also known in some melanized structures, the fossil feathers preserved in DLXH 1218 show a relatively lower level of $\mathrm{Fe}$ than in the surrounding areas, similar to that in the Thermopolis Archaeopteryx. ${ }^{12}$ DLXH 1218 resembles the coliiformes bird in having a very low Fe level in bones, while the bone of the Thermopolis Archaeopteryx is more iron-rich than its feathers. Barden and co-workers ${ }^{32}$ noted that the feathers of the modern marabou stork and white-naped crane did not contain noticeable Fe with EDS (energy dispersive X-ray spectrometry) analyses, and the Fe level was low and varied in two fossilized Gansus feathers. We suspect that the plumage iron level is somewhat influenced by the matrix.

Strontium is strongly present in the bones preserved in DLXH 1218 , which is not surprising as $\mathrm{Sr}$ commonly participates in forming bone bioapatite, and relatively high $\mathrm{Sr}$ levels have also been found in many fossil bone materials. ${ }^{30,40,41,43}$ Different chemical behaviors of $\mathrm{Sr}$ and $\mathrm{Y}$ in calcium phosphates and carbonates have been suggested by Gueriau and co-workers ${ }^{31,43}$ based on fish and non-vertebrate fossils, yet the distribution of $\mathrm{Sr}$ and $\mathrm{Y}$ are congruent in DLXH 1218, as the bones are calcium phosphates only.

\section{$\mathrm{Sr} / \mathrm{Ca}$ variation in different body structures and the fossilization of the claw sheath}

In DLXH 1218, the bony skeleton, claw sheaths and feathers show various $\mathrm{Sr} / \mathrm{Ca}$ ratios. The $\mathrm{Sr} / \mathrm{Ca}$ ratios in most parts of the skeleton are between 0.25 and 0.40 . In contrast, damaged bones usually experience significant calcium removal; while the Sr level remains relatively consistent, causing the $\mathrm{Sr} / \mathrm{Ca}$ ratio generally to be above 0.40 in these damaged parts. This may suggest that the bone surface helped to preserve the $\mathrm{Ca}$ in the bone's postmortem or during fossilization, yet the detailed process remains to be discovered. The $\mathrm{Sr} / \mathrm{Ca}$ ratio in the unguis of DLXH 1218 is around 0.20 , slightly lower than in the bony parts; while the sheath blade has a $\mathrm{Sr} / \mathrm{Ca}$ ratio of around 0.10 , similar to that of the feathers and generally lower than in other parts of the specimen, including the matrix.

The unguis of DLXH 1218 further resembles the bony skeleton by having relatively high levels of $\mathrm{Th}, \mathrm{Ce}$ and $\mathrm{Y}$, while the sheath blade contains lower levels of Th and $\mathrm{Ce}$, and undetectable $\mathrm{Y}$. Nevertheless, the presence of $\mathrm{P}, \mathrm{Ca}, \mathrm{Sr}$, Th and $\mathrm{Ce}$ in the claw sheath and the skeleton suggests that the keratinous unguis and the bony skeleton might share a similar process of fossilization. Saitta and Vinther ${ }^{44}$ proposed two major modes for the keratin preservation in fossils: (a) predominantly organic in anoxic, finegrained sediments via melanosomes or amorphous melanin related components and (b) predominantly as calcium phosphate in coarse-grained, relatively oxic sediments. Chemical mapping of DLXH 1218 indicates that a combination of both modes could happen. The feathers of DLXH 1218 fossilized in mode (a) as typical for most Jehol feather material. The claw sheaths of DLXH 1218 fossilized as calcium phosphate as in mode (b), but in anoxic, fine-grained sediments like other Jehol fossils.

Even though previous studies ${ }^{36,44}$ cannot determine whether the calcium phosphate in the fossilized keratinous structure was endogenous or secondarily precipitated, our results support that the fossilized claw sheaths are at least partially associated to the secondary mineralization of phosphate, with a similar process to the fossilization of the bones. The variation of $\mathrm{Ca}$ and $\mathrm{P}$ among each part of the claw also supports that endogenous phosphates are likely present in the fossilized sheath claws. Chemical mapping revealed that more calcium phosphate was preserved in the fossilized unguis than in the sheath blade in DLXH 1218 (Table S3). Developmental studies showed that in extant archosaurians, the unguis is developed from denser keratinous materials than 
those in the sub-unguis ${ }^{37,}, 38$ and therefore, the enrichment of calcium phosphate in the fossilized unguis compared with the rest of the sheath may be associated with the in vivo calcification of the hardened unguis of DLXH 1218, much like the calcification of dense keratinous structures documented in other extant animals. ${ }^{39}$, 45

\section{CONCLIUSIONS}

This study performed large-area Micro-XRF scanning of the holotype Jianianhualong tengi and, for the first time, obtained the chemical mapping of the whole specimen with a resolution at the micron scale. A detailed analysis of the elemental distribution and compositional variations of the skeleton, feathers and the surrounding matrix demonstrated that the main elements of the organisms such as $\mathrm{S}, \mathrm{P}$ and $\mathrm{Ca}$, as expected, were found to be associated with both the skeleton and the soft tissue remains, while $\mathrm{Ca}$ was relatively higher in the former than in the latter. Some elements, such as $\mathrm{Cu}, \mathrm{Mn}, \mathrm{Ni}$ and $\mathrm{Ti}$, were detected to match the plumage shapes, while other elements, such as $\mathrm{Sr}, \mathrm{Th}, \mathrm{Y}$, and $\mathrm{Ce}$, were strongly associated with the skeleton. Elemental variations within the keratinous claw sheath indicate the possible compositional or ultrastructural difference between the unguis and the sheath blade, and the calcium phosphate in the fossilized claw sheath may be both authigenic and allogenic. A careful examination of the chemical signature of the bones, the claw sheaths and feathers of the Jianianhualong tengi (DLXH 1218) provides new information on the taphonomy of this important fossil and also of the paleobiology of this key species for understanding the evolution of paravians as well as troodontids. It also gave important clues for further study on a few small regions of interest that can be sampled without damaging the specimen.

\section{ASSOCIATED CONTENT}

Please contact the corresponding author for the Supporting Information (Fig. S1-S6 and Table S1-S4). Supplementary figures 1-6, additional information on the XRF analysis; Supplementary tables 1-4 and associated figures, net intensity (cps) of each element of regions of interest.

\section{AUTHOR INFORMATION}

\section{Corresponding Author}

*X. Xu

Email address: xu.xing@ivpp.ac.cn

\section{Author Contributions}

Li JH, Xu X and Teng FF designed the research, Li JH, Tagle R and Yan QQ performed the experiments, Li JH, Pei R and Yan
QQ analyzed the data. All authors contributed ideas and discussed the results. Li JH, Pei R and Xu X wrote the manuscript.

Notes

${ }^{\dagger}$ J.-H. Li and R. Pei contributed equally to this work.

The authors declare no competing financial interest.

\section{ACKNOWLEDGMENTS}

This study was supported financially by the National Natural Science Foundation of China (grants 41890843, 41688103, 41920104009, 41621004 and 41972025), the Laboratory for Marine Geology, Qingdao National Laboratory for Marine Science and Technology (grant MGQNLM201704), and the State Key Laboratory of Palaeobiology and Stratigraphy (Nanjing Institute of Geology and Palaeontology, CAS) (No.193122). We thank Mrs. Wang Lixia for inspiring us with this project. We thank Mr. Meng Liang (DLTV-4), Mr. Wu Baojun (UCAS) and Mrs. Zhang Jiang (CCTV-10) for their assistance in the organization of the research project. We also thank Mrs. Gao Xia and Zhou Jian at the DLXH museum for their assistance in the experiment. We are grateful for Mrs. Su Hui and Sun Liqing at the Boyue Instruments (Shanghai) Co., Ltd. for their efficient job in the instrument coordination. J.H.L. benefited from discussions with colleagues in Office 442 at IGGCAS.

\section{REFERENCES}

1. P. L. Manning, N. P. Edwards, R. A. Wogelius, U. Bergmann, H. E. Barden, P. L. Larson, D. S. Wings, V. M. Egerton, D. Sokaras, R. A. Mori and W. I. Sellers, J. Anal. At. Spectrom., 2013, 28, 1024-1030. https://doi.org/10.1039/C3JA50077B

2. K. Padina and L. M. Chiappe, Biol. Rev., 1998, 73, 1-42. https://doi.org/10.1111/j.1469-185X.1997.tb00024.X

3. X. Xu, Z. Zhou, R. Dudley, S. Mackem, C.-M. Chuong, G. M. Erickson and D. J. Varricchio, Science, 2014, 346, 1253293. https://doi.org/10.1126/science.1253293

4. S. L. Brusatte, R. J. Butler, P. M. Barrett, M. T. Carrano, D. C. Evans, G. T. Lloyd, P. D. Mannion, M. A. Norell, D. J. Peppe, P. Upchurch and T. E. Williamson, Biol. Rev., 2015, 90, 628-642. https://doi.org/10.1111/brv.12128

5. U. Bergmann, P. L. Manning and R. A. Wogelius, Annu. Rev. Anal. Chem., 2012, 5, 361-389. https://doi.org/10.1146/annurev-anchem-062011-143019

6. R. Wogelius, P. Manning, H. Barden, N. Edwards, S. Webb, W. Sellers, K. Taylor, P. Larson, P. Dodson and H. You, Science, 2011, 333, 1622-1626. https://doi.org/10.1126/science. 1205748

7. Q. Li, K.-Q. Gao, J. Vinther, M. D. Shawkey, J. A. Clarke, L. D'Alba, Q. Meng, D. E. G. Briggs and R. O. Prum, Science, 2010, 327, 1369-1372. https://doi.org/10.1126/science.1186290

8. Y. Pan, L. Hu and T. Zhao, Nat. Sci. Rev., 2018, 107, 1040-1053. https://doi.org/10.1093/nsr/nwy107

9. Y. Pan, W. Zheng, A. E. Moyer, J. K. O’Connor, M. Wang, X. Zheng, X. Wang, E. R. Schroeter, Z. Zhou and M. H. Schweitzer, Proc. Natl. Acad. Sci. USA, 2016, 113, E7900-E7907. 
https://doi.org/ 10.1073/pnas.1617168113

10. Y. Pan, W. Zheng, R. H. Sawyer, M. W. Pennington, X. Zheng, X. Wang, M. Wang, L. Hu, J. O'Connor and T. Zhao,

Proc. Natl. Acad. Sci. USA, 2019, 116, 3018-3023. http://doi.org/10.1073/pnas.1815703116.

11. P. L. Manning, N. P. Edwards, U. Bergmann, J. Anné, W. I. Sellers, A. van Veelen, D. Sokaras, V. M. Egerton, R. Alonso-Mori and K. Ignatyev, Nat. Commun., 2019, 10, 1-13. https://doi.org/ 10.1038/s41467-019-10087-2

12. U. Bergmann, R. W. Morton, P. L. Manning, W. I. Sellers, S. Farrar, K. G. Huntley, R. A. Wogelius and P. Larson, Proc. Natl. Acad. Sci. USA, 2010, 107, 9060-9065. https://doi.org/10.1073/pnas.1001569107

13. J. Anné, N. P. Edwards, R. A. Wogelius, R. T.-D. Allison, I. S. William, A. van Veelen, U. Bergmann, D. Sokaras, R. Alonso-Mori, K. Ignatyev, M. E. Victoria and L. M. Phillip, J. Roy. Soc. Interface, 2014, 11, 20140277. https://doi.org/10.1098/rsif.2014.0277

14. V. Rossi, M. E. McNamara, S. M. Webb, S. Ito and K. Wakamatsu, Proc. Natl. Acad. Sci. USA, 2019, 116, 17880-17889. https://doi.org/10.1073/pnas.1820285116

15. P. L. Manning, P. M. Morris, A. McMahon, E. Jones, A. Gize, J. H. S. Macquaker, G. Wolff, A. Thompson, J. Marshall, K. G. Taylor, T. Lyson, S. Gaskell, O. Reamtong, W. I. Sellers, B. E. v. Dongen, M. Buckley and R. A. Wogelius, P. Roy. Soc. Lond B. Bio., 2009, 276, 3429-3437. https://doi.org/10.1098/rspb.2009.0812

16. B. Jiang, T. Zhao, S. Regnault, N. P. Edwards, S. C. Kohn, Z. Li, R. A. Wogelius, M. J. Benton and J. R. Hutchinson, Nat. Commun., 2017, 8, 14779. https://doi.org/10.1038/ncomms14779

17. Y. C. Lee, C. C. Chiang, P. Y. Huang, C. Y. Chung, T. D. Huang, C. Wang, C. Chen, R. Chang, C. Liao and R. R. Reisz, Nat. Commun., 2017, 8, 1-8. https://doi.org/ 10.1038/ncomms 14220

18. N. P. Edwards, A. Van Veelen, J. Anné, P. L. Manning, U. Bergmann, W. I. Sellers, V. M. Egerton, D. Sokaras, R. Alonso-Mori, K. Wakamatsu, S. Ito and R. A. Wogelius, Sci. Rep-UK, 2016, 6, 34002. https://doi.org/10.1038/srep34002

19. Q. Ji, P. J. Currie, M. A. Norell and S. A. Ji, Nature, 1998, 393, 753-761. https://doi.org/10.1038/31635

20. X. Xu, X. L. Wang and X. C. Wu, Nature, 1999, 401, 262-266. https://doi.org/10.1038/45769

21. X. Xu, X. T. Zheng, C. Sullivan, X. L. Wang, L. D. Xing, Y. Wang, X. M. Zhang, J. K. O'Connor, F. C. Zhang and Y. H. Pan, Nature, 2015, 521, 70-73. https://doi.org/10.1038/nature14423

22. M. Wang, J. K. O'Connor, X. Xu and Z. Zhou, Nature, 2019, 569 , 256-259. https://doi.org/10.1038/s41586-019-1137-z

23. Q. Zhao, M. J. Benton, S. Hayashi and X. Xu, Acta Palaeontol. Pol., 2019, 64, 323-334. https://doi.org/10.4202/app.00559.2018

24. X. Xu, P. Currie, M. Pittman, L. Xing, Q. Meng, J. Lü, D. Hu and C. Yu, Nat. Commun., 2017, 8, 14972. https://doi.org/10.1038/ncomms14972

25. M. Alfeld, J. V. Pedroso, M. van Eikema Hommes, G. Van der Snickt, G. Tauber, J. Blaas, M. Haschke, K. Erler, J. Dik and K. Janssens, J. Anal. At. Spectrom., 2013, 28, 760-767. https://doi.org/ 10.1039/C3JA30341A

26. J. R. Duivenvoorden, A. Käyhkö, E. Kwakkel and J. Dik, Heritage Sci., 2017, 5, 6. https://doi.org/10.1186/s40494-017-0117-6
27. S. Saverwyns, C. Currie and E. Lamas-Delgado, Microchem. J., 2018, 137, 139-147. https://doi.org/10.1016/j.microc.2017.10.008

28. D. S. Bright, and D. E. Newbury, J. Microsc., 2004, 216, 186-193. https://doi.org/10.1111/j.0022-2720.2004.01412.x

29. S. Aida, T. Matsuno, T. Hasegawa and K. Tsuji, Nucl. Instrum. Meth. B, 2017, 402, 267-273. https://doi.org/10.1016/j.nimb.2017.03.123

30. V. M. Egerton, R. A. Wogelius, M. A. Norell, N. P. Edwards, W. I. Sellers, U. Bergmann, D. Sokaras, R. Alonso-Mori, K. Ignatyev, A. van Veelen, J. Anné, B. van Dongen, F. Knoll and P. L. Manning, J. Anal. At. Spectrom., 2015, 30, 627-634. https://doi.org/10.1039/C4JA00395K

31. P. Gueriau, C. Jauvion and C. Mocuta, Palaeontology, 2018, 61, 981-990. https://doi.org/10.1111/pala.12377

32. H. E. Barden, R. A. Wogelius, D. Li, P. L. Manning, N. P. Edwards and B. E. van Dongen, PLoS One, 2011, 6, 25494. https://doi.org/ 10.1371/journal.pone.0025494

33. M. Niecke, M. Heid and A. Krüger, J. Ornithol., 1999, 140, 355362. https://doi.org/10.1007/bf01651032

34. X. Zheng, J. O'Connor, X. Wang, M. Wang, X. Zhang and Z. Zhou, Proc. Natl. Acad. Sci. USA, 2014, 111, 13900-13905. https://doi.org/10.1073/pnas.1411070111

35. E. T. Saitta, I. Fletcher, P. Martin, M. Pittman, T. G. Kaye, L. D. True, M. A. Norell, G. D. Abbott, R. E. Summons, K. Penkman and J. Vinther, Org. Geochem., 2018, 125, 142-151. https://doi.org/10.1016/j.orggeochem.2018.09.008

36. E. Moyer Alison, W. Zheng and H. Schweitzer Mary, P. Roy. Soc. Lond B. Bio., 2016, 283, 20161997. https://doi.org/10.1098/rspb.2016.1997

37. L. Alibardi, Ann. Anat., 2020, 231, 151513. https://doi.org/10.1016/j.aanat.2020.151513

38. L. Alibardi, Anat. Sci. Int., 2020, 84, 189-199. https://doi.org/10.1007/s12565-009-0015-4

39. A. Book, and R. H. Champion, Progress in the biological sciences in relation to dermatology-2. Cambridge, Cambridge University Press, 1964.

40. W. E. Cabrera, I. Schrooten, M. E. De Broe and P. C. D'Haese, J. Bone Miner. Rev., 1999, 14, 661-668. https://doi.org/10.1359/jbmr.1999.14.5.661

41. M. B. Goodwin, P. G. Grant, G. Bench and P. A. Holroyd, Palaeogeogr. Paleoclimat. Paleoecol., 2007, 253, 458-476. https://doi.org/10.1016/j.palaeo.2007.06.017

42. M. H. Schweitzer, Annu. Rev. Earth Pl. Sc., 2011, 39, 187-216. https://doi.org/10.1146/annurev-earth-040610-133502

43. P. Gueriau, C. Mocuta, D. B. Dutheil, S. X. Cohen, D. Thiaudiere, S. Charbonnier, G. Clement, L. Bertrand and O. Consortium, PLoS One, 2014, 9, 86946. https://doi.org/ 10.1371/journal.pone.0086946

44. E. T. Saitta, and V. Jakob, Palaeontol. Electron., 2019, 22.3.2E, 1-30. https://doi.org/10.26879/1017E

45. P. R. Blakey, C. Earland, and J. P. G. Stell, Nature, 1963, 198, 81 https://doi.org/10.1038/198481a0 